\title{
Increasing efficiency in ethanol distillation on small scale
}

\author{
F. D. MAYER ${ }^{1}$, G. F. SCHETTERT ${ }^{1}$, P. R. S. SALBEGO ${ }^{1}$, V. BALDO ${ }^{1}$, M. A. MAZUTTI ${ }^{1}$, \\ R. HOFFMANN ${ }^{1}$ \\ ${ }^{1}$ Universidade Federal de Santa Maria, Departamento de Engenharia Química \\ E-mail para contato: flaviodmayer@yahoo.com.br
}

\begin{abstract}
This work examines experimentally the performance of a distillation column using a solution of ethanol and water as a feed. The limits for the concentration and flow rate of the feed solution in the column were established to be $5-9 \%$ by volume and $1848-4385 \mathrm{~g} \cdot \mathrm{h}^{-1}$, respectively. Eleven tests were performed, each with three samples. Statistical analysis was performed to assess if the independent variables influenced the production of ethanol in accordance with Brazilian legislation, i.e., a Hydrous Ethanol Fuel with ethanol concentration between 92.5 and $93.8 \%$ by mass. The influence of the feed stream ethanol concentration and flow rate were significant for both the top product concentration and the recovery ratio. The recovery ratio of ethanol was above $80 \%$ in 10 out of 11 tests, demonstrating that the performance of the column is satisfactory.
\end{abstract}

Keywords: hybrid distiller, ethanol distillation, efficiency

\section{INTRODUCTION}

Ethanol fuel production plays an important role in the Brazilian economy. In 2010, the alcohol and sugar sector accounted for $19.1 \%$ of the primary energy supply (EPE, 2011). This is due largely to the National Alcohol Program (PROALCOOL), whose incentives have transformed ethanol fuel into an alternative to gasoline (Oliveira, 2002; Rico et al., 2010; Rosillo-Calle \& Cortez, 1998; Sorda et al., 2010). Considered the largest program for ethanol production in the world (Oliveira, 2002), leading Brazil to be an important player in the international ethanol trade market (Rajcaniova et al., 2013). The competitiveness of ethanol fuel compared with gasoline encouraged the popularization of vehicles with flex-fuel engines. Since 2003, 18.5 million light vehicles with this technology have been manufactured (ANFAVEA, 2013), and they will account for $47 \%$ of the national fleet in 2015 (Sorda et al., 2010). This scenario favors the increase in demand and also in the price of ethanol fuel (Du and Carriquiry, 2013), leading to a grown in the HEF production.

However, this rise in the ethanol production - considering the traditional, large-scale model has some associated disadvantages such as land concentration (Hira, 2010; Veiga-filho and Ramos, 2006) and rural exodus (Ortiz et al., 2006), economic and social risks of monoculture (Ribeiro, 2013), the food versus biofuel dilemma (Harvey and Pilgrim, 2011; Runge and Senauer, 2007), and environmental pressures (Azadi et al., 2012; Buyx \& Tait, 2011), although the latter question has been more clearly resolved, according to various studies (Janssen \& Rutz, 2011; Nuñez et al., 2013; Walter et al., 2011).

In some regions, the expansion in the ethanol production should be adapted to the local conditions of topography and landholding, as has been the case in the southern Brazilian state of 


\section{9 a 22 de outubro de 2014 \\ Florianópolis/SC}

Congresso Brasileiro de

Rio Grande do Sul. A differentiated model is designed for this state, based on small-scale ethanol production as complementary activity, integrating both production of energy and food. This requires, in addition to governmental incentive projects, technological development of equipments and processes for the production of ethanol, especially regarding to the distillation column. This unit comprises the largest share of energy consumption and has a high potential to increase its efficiency.

Ethanol production on small scale presents low yields, especially in the distillation step, and also, as observed in previous studies from our research group, the performance of the distillation column has an efficiency of approximately 66\% in the ethanol recovery (Mayer et al., 2013). In order to solve this problem, we propose a hybrid distiller, which uses Vigreaux and Raschig rings in the sections of stripping and rectification, respectively.

Based on these aspects, the aim of this work is to improve the performance of ethanol distillation using a bench scale column by means of experimental design methodology. For this purpose, experiments were carried out to evaluate the influence of the feed ethanol concentration and flow rate on the top and bottom products ethanol concentrations, according to the legal requirements imposed on the market.

\section{MATERIALS AND METHODS}

\subsection{Apparatus and experimental procedure}

The study consisted in the operation analysis of a bench scale distillation column by varying the feeding ethanol concentration and mass flow rate using a standard solution of ethanol and water. Therefore, the same distillation apparatus as proposed in our previously research was used (Mayer et al., 2013). The distiller consists of a glass bench distiller with a $190 \mathrm{~cm}$ effective height and $4 \mathrm{~cm}$ inner diameter that is divided in three modules. The distillation apparatus has a feed preheat tank, a peristaltic pump for feeding, a reboiler, composed of a submerged electrical resistor and an external heating mantle, a fractionating column divided in stripping and rectification modules with Vigreux and Raschig rings, respectively, a condenser, and a reflux heating tank, besides temperature and pressure sensors along the distiller, connected to a programmable logic controller.

The product samples from the top and bottom were taken in triplicate every 15 minutes throughout the operation of the distiller. The samples were directly analyzed on a digital densimeter (Anton Paar DMA $4500 \mathrm{M}$ ), with sample temperature adjustment $\left(20{ }^{\circ} \mathrm{C}\right.$ ) and repeatability of $0.00001 \mathrm{~g} \cdot \mathrm{cm}^{3}$.

The desired minimum concentration for the top product was set according to the Brazilian National Agency of Petroleum, Natural Gas and Biofuels (ANP) resolution 07/2011 (ANP, 2011), which establishes a ethanol mass fraction equal to $92.5 \%$ in ethanol fuel (and a volume fraction equivalent to $95.1 \%$ ). The desired ethanol concentration for the bottom product was limited to 0.5 wt $\%$ (volume fraction equal to $0.69 \% \mathrm{v} / \mathrm{v}$ ) to avoid excessive losses of ethanol. The top and bottom values combined result in $92 \%$ of ethanol recovery.

\subsection{Statistical analysis}

The effects of feed stream ethanol concentration and mass flow rate on the top and bottom products concentrations were evaluated by means of a central composite rotatable design (CCRD) for two independent variables, with a total of eleven experimental runs. Table 1 presents the levels 
of each independent variable investigated. All results were analyzed using Statistica ${ }^{\circledR}$ 7.0 (Statsoft Inc, Tulsa, OK, USA) considering a significance level of $90 \%(\mathrm{p}<0.10)$.

Table 1 - Mean ethanol concentration for top (Y1) and bottom (Y2) products, reflux rate and ethanol recovery efficiency from the experiments, at atmospheric pressure.

\begin{tabular}{|c|c|c|c|c|c|c|}
\hline \multirow[t]{2}{*}{ Run } & \multirow{2}{*}{$\begin{array}{c}\text { Feed ethanol } \\
\text { concentration }(\mathrm{wt} \%)\end{array}$} & \multirow{2}{*}{$\begin{array}{l}\text { Feed flow rate } \\
\qquad\left(\mathrm{kg} \cdot \mathrm{h}^{-1}\right)\end{array}$} & \multicolumn{2}{|c|}{$\begin{array}{c}\text { Ethanol } \\
\text { concentration }(\mathrm{wt} \%)\end{array}$} & \multirow{2}{*}{$\begin{array}{l}\text { Reflux } \\
\text { rate }\end{array}$} & \multirow{2}{*}{$\begin{array}{c}\text { Recovery } \\
\text { Efficiency (\%) }\end{array}$} \\
\hline & & & Top & Bottom & & \\
\hline 1 & $4.1(-1)$ & $2.20(-1)$ & 91.33 & 0.95 & 6.95 & 79.02 \\
\hline 2 & $6.3(1)$ & $2.20(-1)$ & 90.82 & 1.86 & 2.87 & 83.78 \\
\hline 3 & $4.1(-1)$ & $3.93(1)$ & 88.17 & 0.69 & 1.94 & 94.99 \\
\hline 4 & $6.3(1)$ & $3.93(1)$ & 89.77 & 2.63 & 1.26 & 83.14 \\
\hline 5 & $3.7(-1.41)$ & $3.02(0)$ & 88.55 & 0.21 & 3.91 & 90.93 \\
\hline 6 & $6.7(1.41)$ & $3.02(0)$ & 90.65 & 0.51 & 3.81 & 83.50 \\
\hline 7 & $5.2(0)$ & $1.85(-1.41)$ & 89.67 & 1.27 & 4.06 & 84.21 \\
\hline 8 & $5.2(0)$ & $4.39(1.41)$ & 90.40 & 0.31 & 3.32 & 81.75 \\
\hline 9 & $5.2(0)$ & $3.02(0)$ & 91.36 & 1.59 & 3.39 & 80.70 \\
\hline 10 & $5.2(0)$ & $3.02(0)$ & 92.01 & 1.34 & 3.77 & 81.27 \\
\hline 11 & $5.2(0)$ & $3.02(0)$ & 92.39 & 1.02 & 3.58 & 81.60 \\
\hline
\end{tabular}

\section{RESULTS AND DISCUSSION}

Table 1 presents the top and bottom products concentrations as well the recovering efficiency obtained in the CCRD. The ethanol concentration in the column top ranged from 88.17 wt $\%$ (run 3) to $92.39 \mathrm{wt} \%$ (run 11), when the bottom ethanol concentration ranged from $0.21 \mathrm{wt} \%$ (run 5) to $2.63 \mathrm{wt} \%$ (run 4). The recovering efficiency ranged from $79.02 \%$ (run 1) to $94.99 \%$ (run 3). From these results it is verified that the experimental condition that led to the highest recovering efficiency (run 3) is not in agreement to the Brazilian regulation in relation to the top concentration. Moreover, the highest ethanol concentration was obtained in a condition where the bottom ethanol concentration was too high for a small scale ethanol production, with recovery efficiency around $80 \%$.

The analysis of the distillation operation as a function of the ethanol concentration in the feed - which results from both ethanol concentration and feed flow rate - reveals an important relationship with the reflux ratio. From Table 1 data, it was observed that by increasing the feed ethanol/water feed ratio the reflux ratio is decreased. This can be explained by the mass balance within the distiller: higher amount of ethanol implies a greater production of top product, in order to keep the recovery ratio constant. Because the distiller operation has always worked close to its maximum capacity (liquid and vapor flows do not change between the experiments), increasing 
the top product withdrawal decreases the reflux ratio (L/D).

Although the concentrations obtained for the top products had similar values (average mass fraction of $90.46 \% \pm 1.34$ ), there was a small relationship between the reflux ratio and the top product concentration. The efficiency of packing columns with finite reflux, as stated by Kister (1992), is similar to the efficiency with total reflux. For that reason, it is expected that the efficiency in the packed column would be influenced only minimally by the reflux ratio, resulting in a small variation in the concentration of the top product. This behavior could be verified by comparing the following runs: (1) and (3), where the feed concentration is maintained at a constant value, varying the feed flow rate. The reflux ratio in run (1) was approximately 3.5 times greater than in run (3) and the ethanol concentration in the top and bottom products were lower in run (3); And (9), (10), and (11), which one represents the central point of the study, with equal feed concentration and feed flow rates, resulting in similar reflux ratios and, consequently, in similar concentrations to the top product.

It is also possible to note, by means of runs (5) and (6), that, by varying the feed concentrations at the extremes of the experimental planning, i.e., 3.7 and $6.7 \mathrm{wt} \%$, there was no significant variation in the top product concentration nor in the bottom product concentration, showing that the extreme concentrations are poor operational conditions for the distiller. As for the bottom product, only runs (5) and (8) resulted in a concentration within the established limit, possibly due to the difficulty caused by the use of a Vigreux type column in the stripping section. This is the reason of tests using solutions of 4.1 and $5.2 \mathrm{wt} \%$. Flooding in the tower was also observed when, for some feed concentrations, the power of the heating mantle was higher than $50 \%$ of the heating power. The flooding point was premature probably because of bottlenecks between the modules connection.

The experimental results presented in the Table 1 were used to establish the effects of the studied variables. The effects were expressed in the form of Pareto chart, which are presented in the Figure 1.a, b, and c. For the top product concentration, the quadratic terms for feed concentration and mass flow rate were statistically significant (Figure 1.a), whereas other terms as linear and interaction were not significant in the studied range $(\mathrm{p}<0.1)$. The negative signs of the quadratic terms indicate the presence of a maximum point (Figure 2.a). For the bottom ethanol concentration, it was observed that neither of the studied variables (concentration and feeding flow rate) was significant in the evaluated range, indicating that regardless the values of the process variables the bottom concentration is statistically the same, probably due to the design of the stripping section (Vigreux). For recovery efficiency, linear and quadratic terms for feed concentration as well the interaction between the feed concentration and mass flow rate were statistically significant $(\mathrm{p}<0.1)$. Increasing the feed concentration led to a decrease in the recovery efficiency, whereas the positive sign of quadratic term for feed concentration indicates the presence of a minimum point in the system. 


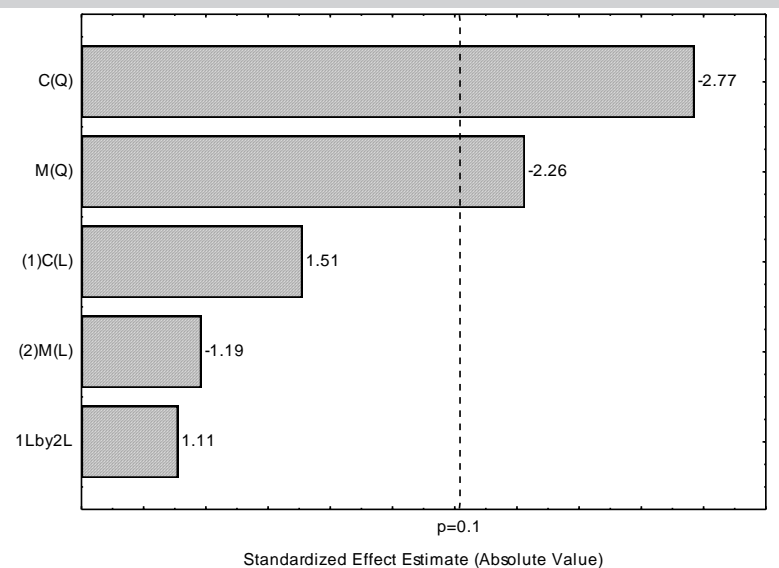

a)
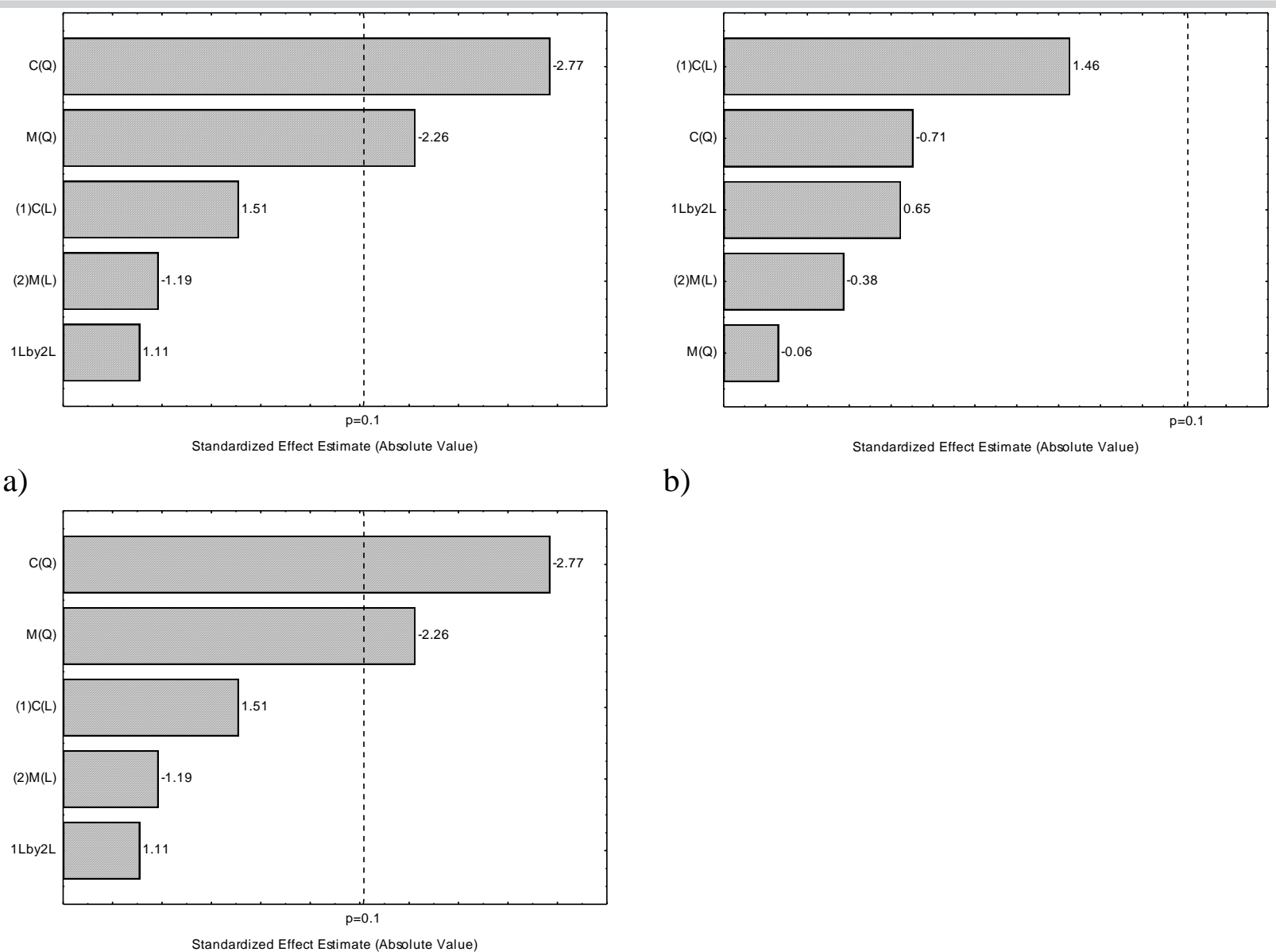

b)

c)

Figure 1 - Pareto Chart showing the effects of linear, quadratic and interaction terms of independent variables on top ethanol concentration (a), bottom ethanol concentration (b) and recovery efficiency $(\mathrm{c})$.

In order to improve the experimental conditions to obtain a maximum top product concentration and also higher recovery efficiency, two empirical models are presented. Eq. 1 presents the significant terms $(\mathrm{p}<0.1)$ concerning to ethanol concentration in the top product, and Eq. 2 represents the recovery efficiency.

$$
\begin{aligned}
& \text { Eth }=91.92-1.11 \cdot C^{2}-0.17 \cdot M^{2} \\
& \phi=84.72-2.20 \cdot C+3.06 \cdot C^{2}-4.15 \cdot C \cdot M
\end{aligned}
$$

Where Eth is the ethanol concentration in the top product (wt \%), $\phi$ is the recovery efficiency, $\mathrm{C}$ and $\mathrm{M}$ are the coded feed concentration and mass flow rate, respectively. These models were validated by analysis of variance (ANOVA). The calculated F-test for Eq. 1 and 2 were about 1.7 and 1.3 times greater than the tabulated ones for significance at $p=0.1$, and the determination coefficients $\left(\mathrm{R}^{2}\right)$ were 0.7474 and 0.7942 , respectively. The high values for the determination coefficient indicate good fitting of experimental data, allowing the use of such models to predict process performance as well as to use them as tool for process optimization.

Figure 2.a shows the contour curve response for the top product concentration. It is possible to observe the existence of an optimum operational region with high top product concentration as a function of feed ethanol concentration and feed flow rate. This region is located at a feed 
concentration ranging from 5.0 and $5.8 \mathrm{wt} \%$ and at a feed flow rate from 2.85 and $3.20 \mathrm{~kg} \cdot \mathrm{h}^{-1}$. It is important to mention that in this optimum operational region would be possible to obtain a top product ethanol concentration in accordance with the ANP regulation 7/2011 (ANP, 2011).

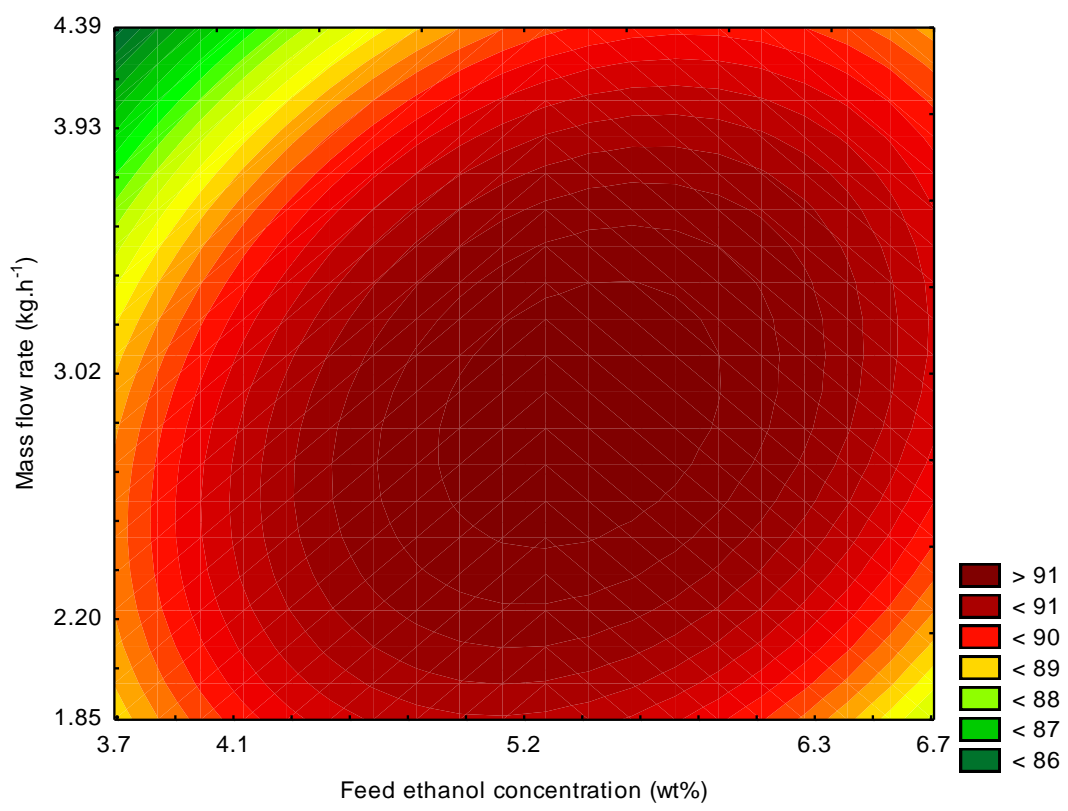

a)

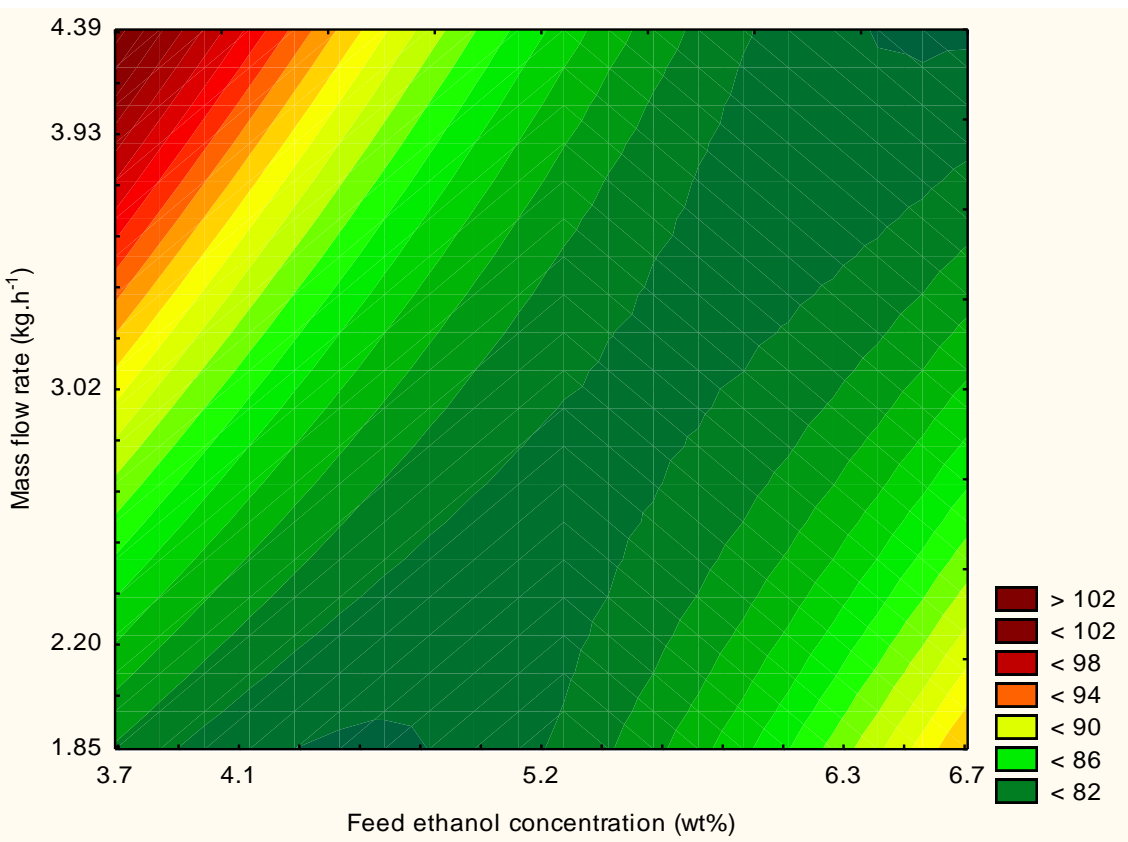

b)

Figure 2. Contour plots showing the influence of independent variables on top ethanol concentration (a) and recovery efficiency (b).

Nevertheless, the recovery effectiveness at the optimized region for top ethanol concentration was between 82 to $86 \%$ (Figure 2.b). The highest recovery efficiency was obtained at a feed ethanol concentration around $4 \mathrm{wt} \%$ and feed flow rate ranging from 3.50 to $4.39 \mathrm{~kg} \cdot \mathrm{h}^{-1}$. However, the most important result was the operational variables optimization that allows attaining the top 
product concentration in accordance with the Brazilian legislation.

\section{CONCLUSIONS}

The analysis of the experiments in the distillation column demonstrates that the top product concentration (dependent variable) was influenced by the independent variables: feed ethanol concentration and flow rate. Therefore, it was possible to establish an optimum operating region for the hybrid distiller. This requires a good quality control on fermentation step and in the operating conditions of distillation in way to obtain a product suitable for the market.

However, it was verified that the independent variables - or their interaction - had no significant influence on the bottom product concentration, in any of its forms (linear and quadratic), showing that the effects were not relevant for the stripping section.

The experimental design methodology proved to be an important tool to improve the operation of a bench scale distillation column. In this work, it was experimentally obtained ethanol fuel with concentration near the Brazilian legislation $(92.5 \mathrm{wt} \%)$ with a feed concentration ranging from 5.0 to $5.8 \mathrm{wt} \%$ ethanol and feed flow rate from 2.85 to $3.20 \mathrm{~kg} \cdot \mathrm{h}^{-1}$. The performance of the hybrid distiller was satisfactorily demonstrated by the ethanol recovery efficiency, reaching at least $80 \%$ in ten of the eleven tests and over $90 \%$ in two of them. Also, it was found a recovery ratio around $83 \%$ in the optimized condition, which reinforces its good results compared with common systems for producing ethanol on a small-scale. No evidence of effective interference of reflux ratio on top and bottom products was observed.

\section{ACKNOWLEDGMENT}

Financial support is acknowledged by CAPES (Coordination of Improvement of Higher Education Personnel) and the Ministry of Science, Technology and Innovation (MCTI) (process number 01200.001972/2010-16).

\section{REFERENCES}

ANFAVEA, 2013. Brazilian Automotive Industry Yearbook - 2013. Brazilian Automotive Industry Association, São Paulo.

ANP, 2011. Resolução ANP n_ 07, Fevereiro, 09, 2011. Agência Nacional de Petróleo, Gás Natural e Biocombustíveis. Available http://www.anp.gov.br/NXT/gateway.dll?f=templates\&fn=default.htm\&vid=anp:10.1048/enu.

Azadi, H., De Jong, S., Derudder, B., De Maeyer, P., Witlox, F., 2012. Bitter sweet: How sustainable is bio-ethanol production in Brazil? Renew. Sustain. Energy Rev. 16, 3599-3603.

Buyx, A.M., Tait, J., 2011. Biofuels : ethics and policy-making. Biofuels, Bioprod. Biorefining 5, 631639.

Du, X., Carriquiry, M. a., 2013. Flex-fuel vehicle adoption and dynamics of ethanol prices: lessons from Brazil. Energy Policy 59, 507-512.

Energy Research Office, 2011. Brazilian Energy Balance. Rio de Janeiro.

Harvey, M., Pilgrim, S., 2011. The new competition for land: Food, energy, and climate change. Food Policy 36, S40-S51. 
Hira, A., 2010. Sugar rush: Prospects for a global ethanol market. Energy Policy 39, 6925-6935.

Janssen, R., Rutz, D.D., 2011. Sustainability of biofuels in Latin America: Risks and opportunities. Energy Policy 39, 5717-5725.

Kister, H.Z., 1992. Distillation Design. McGraw-Hill, New York.

Mayer, F.D., Hoffmann, R.S., Hoffmann, R., 2013. An Innovative Project Involving an Appropriate Hybrid Distillation System for Small-Scale Ethanol Fuel Production. Chem. Eng. Commun. 200, 563-574.

Nuñez, H.M., Önal, H., Khanna, M., 2013. Land use and economic effects of alternative biofuel policies in Brazil and the United States. Agric. Econ. 44, 487-499.

Oliveira, J.A.P. De, 2002. The policymaking process for creating competitive assets for the use of biomass energy: the Brazilian alcohol programme. Renew. Sustain. Energy Rev. 6, 129-140.

Ortiz, L., Schlesinger, S., Noronha, S., 2006. Agronegócios e biocombustíveis: uma mistura explosiva. Rio de Janeiro.

Rajcaniova, M., Drabik, D., Ciaian, P., 2013. How policies affect international biofuel price linkages. Energy Policy 59, 857-865.

Ribeiro, B.E., 2013. Beyond commonplace biofuels: Social aspects of ethanol. Energy Policy 57, 355362.

Rico, J. a P., Mercedes, S.S.P., Sauer, I.L., 2010. Genesis and consolidation of the Brazilian bioethanol: A review of policies and incentive mechanisms. Renew. Sustain. Energy Rev. 14, 1874-1887.

Rosillo-Calle, F., Cortez, L.A.B., 1998. Towards PROALCOOL II - Review of the Brazilian bioethanol programme. Biomass and Bioenergy 14, 115-124.

Runge, C.F., Senauer, B., 2007. How Biofuels Could Starve the Poor [WWW Document]. Foreign Aff. URL http://www.foreignaffairs.com/articles/62609/c-ford-runge-and-benjamin-senauer/howbiofuels-could-starve-the-poor

Sorda, G., Banse, M., Kemfert, C., 2010. An overview of biofuel policies across the world. Energy Policy 38, 6977-6988.

Veiga-filho, A.A., Ramos, P., 2006. The Brazilian national alcohol program and evidence of concentration in sugar cane production and processing. Informações Econômicas 36, 48-61.

Walter, A., Dolzan, P., Quilodrán, O., De Oliveira, J.G., Da Silva, C., Piacente, F., Segerstedt, A., 2011. Sustainability assessment of bio-ethanol production in Brazil considering land use change, GHG emissions and socio-economic aspects. Energy Policy 39, 5703-5716. 